\title{
Concept Analysis of Nursing Wisdom
}

\author{
Najla A Barnawi* \\ College of Nursing, Saudi Arabia
}

*Corresponding author: Najla A Barnawi, College of Nursing-Riyadh, King Saud Bin Abdulaziz University for Health Sciences, Saudi Arabia

\section{ARTICLE INFO}

Received: 慧 November 11, 2019

Published: 蔧 November 21, 2019

Citation: Najla A Barnawi. Concept Analysis of Nursing Wisdom. Biomed J Sci \& Tech Res 23(1)-2019. BJSTR. MS.ID.003859.
ABSTRACT

Wisdom is the heart of developing a personal philosophy that impulses the individual to seek true knowledge. Exploring wisdom in nursing profession is an essential element as it is construct the nursing identity. Philosophically, nursing wisdom should be explored and discussed as a new phenomenon in nursing discipline. Nursing as a discipline has needed to traverse various historical and social controversies that blur the image of nursing identity within the healthcare context. The over- Medicalized model, which frames the current healthcare system, obscures the core value of nursing profession, which aims to deliver holistic care. The aim of this concept analysis is to propose nursing wisdom as a new concept in nursing discipline. In conclusion, understanding the concept of nursing wisdom improves the professional identity and autonomy by empowering accurate nursing knowledge and epistemic knowing process. The study findings demonstrate that, there are four major dimensions that include the concept of wisdom in nursing profession. These dimensions are moral and ethical aspects, nursing managements and leadership, clinical nursing experiences and nursing education.

\section{Introduction}

Gaining wisdom is an ongoing lifelong learning process that takes one toward a deeper understanding of the truth [1]. Wisdom, knowing, and truth relate to each other in a way that allows one to discover new concepts, paradigms, and theories about various life experiences [2]. Wisdom is the heart of developing a personal philosophy that impulses the individual to seek true knowledge. Aristotle famously wrote, "knowing yourself is the beginning of all wisdom" [3]. This indicates that wisdom is a "long-standing dualism between body and mind" that reveals self-discovery [4] Thus, initiating wisdom develops through acknowledging a firm identify, which helps individuals to provide reflective judgments in uncertain circumstances. Identity is introduced in philosophical debates as a "primitive relational expression [5] that sustains certainty of self-knowing [4]

It is logical to assume that nursing has its own wisdom, which is framed by a unique nursing identity. Therefore, exploring wisdom in nursing profession is an essential element as it is construct the nursing identity. Philosophically, nursing wisdom should be explored and discussed as a new phenomenon in nursing discipline. Nursing as a discipline has needed to traverse various historical and social controversies that blur the image of nursing identity within the healthcare context [6]. Understanding nursing wisdom is one of these concepts that empower professionalism in nursing discipline $[7,8]$. It constructs the nursing knowledge in a way that provides reflective judgments in different, complex and uncertain nursing experiences [9]. Though, it is difficult to be defined and comprehend; it needs deeper investigation and insight [9]. Understanding what constitutes wisdom is fundamental to clarify nursing identity and the true meaning of professionalism [10].

This helps the healthcare personnel and nursing scholars to realize the core value of nursing as a discipline and as a profession. Nursing as a discipline has various historical and social controversies that blur the image of nursing identity within the healthcare context [6]. The over- Medicalized model, which frames the current healthcare system, is one of those controversies. It obscures the core value of nursing profession, which aims to deliver holistic care [11]. This pervasive medicalized model is comprised of understanding human health as an existence of a disease or pathological condition $[11,12]$. Thus, narrows the scope of care practice and the autonomy of nursing as a profession [12,13]. Indeed, it contredits with the core value of nursing discipline, which aims to maintain the human wellness and to deliver a holistic care 
$[11,12]$. The holistic care in nursing profession rose from art and science approaches, which create various nursing paradigms and a massive body of nursing knowledge [14-19].

Though, all types of nursing paradigms fall under one of the two categories, which are empiricist or interpretative paradigms [17]. Nursing knowledge in the empiricist paradigm is a transform of medicalized model. The knowledge in this paradigm has observational and tactical base, which develops through the experiences [18]. It is analysed through the lens of empiricism and logical positivism views $[17,18]$. Epistemologically, this increases the objective grounds of nursing knowledge. This objectivity generates and generalizes standardized nursing care [20]. Some nurses questioned and challenged the empiricist paradigm because it underestimates the importance of other forms of knowledge that supports the holistic care such as personal, perceptive, and ethical knowledge $[17,18]$. In contrast, nursing knowledge in the interpretative paradigm develops from the social model that is grounded in postpositivism [21-23].

The knowledge in the interpretative paradigm has a reaction base that accepts various interpretations as truth. Accordingly, the development of knowledge in this paradigm requires social interaction and human experiences [17,23]. It is analysed through the lens of constructivism and interpretivism views [24]. Epistemologically, this enhances reflexive subjectivity bases in nursing knowledge, which critically explores different meaning of professionalism in nursing care $[17,24,25]$. The aim of this concept analysis is to propose nursing wisdom as a new concept in nursing discipline (Concept Map) (Figure 1). Furthermore, it describes the different views, classifications, knowledge attributes and types of wisdom in nursing. A better understanding of nursing wisdom and its attributes are essential for learning how to understand the meaning of competent care which is essential to recognize nursing identity and the meaning of professionalism.

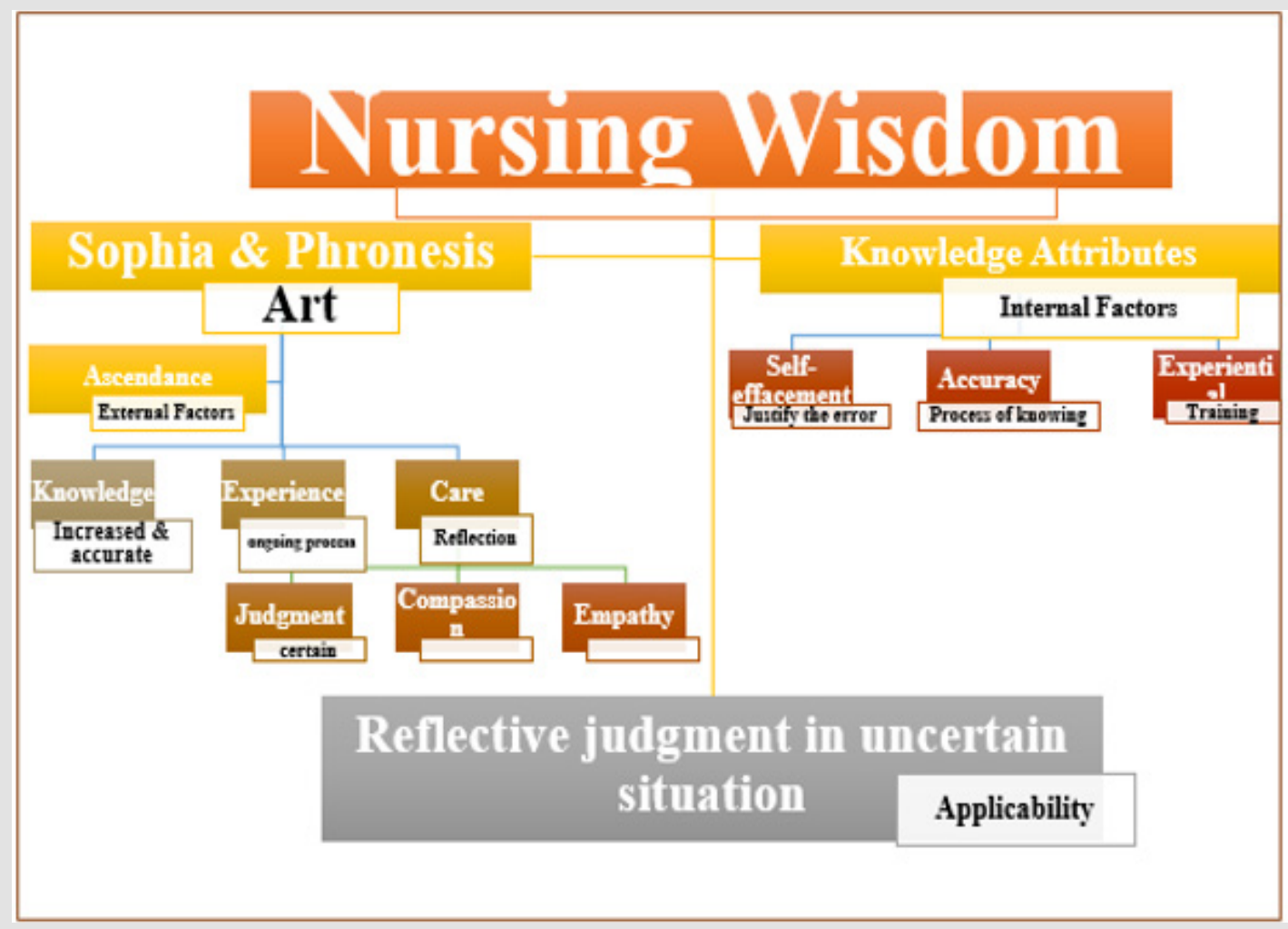

Figure 1: Nursing Wisdom Concept Map viewing window.

\section{Materials and Methods}

Rodgers' evolutionary method [26] is utilized to conduct the proposed concept analysis. This method is based on philosophical positions that view a concept as an abstracted phenomenon that requires further expression [26,27]. Furthermore, scholars use this method to consider that the idea or the abstracted concepts change over time, either by convention or by purposeful definition [26,27]. This allows further investigation for this new innovated concept nursing wisdom to be clarified in the future. Furthermore, this method stresses the belief that concepts are affected by contextual factors [26]. Therefore, the goal of evolutionary concept analysis is to 'clarify and develop' concepts rather than describe their essence [26]. The method of evolutionary concept analysis is an ideal model that suits the goals of the proposed concept. The strength of the method is that it is systematic and provides a structured framework designed to identify the antecedents and attributes of nursing wisdom in nursing discipline [28]. 


\section{Sample}

An integrative literature review was conducted to identify the available evidences that address the role of wisdom in nursing discipline. While this review is not a systematic review per se, however, the essential principles of systematic review methodology of University of York report No. 4 is used to formulate a clear search strategy, identify appropriate inclusion and exclusion criteria of the selected articles, identify the best method for data extraction, and identify the accurate method to assess the quality to the data [29]. Integrating accurate data is essential in this topic "nursing wisdom" and it coherence with the study objectives because it facilitates the following; summary about the available research and draws overall conclusions from the body of included literature; illustrate the included studies that address related or identical assumption; and finally meets the same standards as primary research in regard to clarity, rigor, and replication.

\section{Search Strategy}

The literature search for this study was accomplished by searching the following terms "wisdom," "clinical wisdom," "practical wisdom," "professional wisdom," "nursing," and "nurses" in CINHAL, Medline, and PubMed databases. The searches were directed at identifying references that met the following criteria: published in English between 1995 up to date; having the nursing context; having sufficient evidence/conclusions about the intended objective of this study. The focus mainly on the most relevant and highest quality research studies and reviews; though the low quality studies are also included to increase the robustness of this study.

\section{Screening Procedure \& Quality Appraisal}

Two main steps were used to select eligible studies for this review and include the following; first, title and abstract screening, at this stage the titles as well as the abstract of the papers in each database were examined. This stage assesses the eligibility for inclusion criteria based on the key words of the study. Indeed, each included abstract was screened for its aim and/or the conclusion from the study, the context/settings of the study, and the type of participants. Second step is, full text screening, all included abstracts were critically analyzed to identify the main attributes that concern "Nursing Wisdom" based on Carper's pattern of knowledge. The quality of the articles is appraised by using Critical Appraisal Skills Program (CASP tool)2. This tool assesses the research methodological quality of the articles [30]. The CASP checklist tool is selected according to the study design. The evaluation process was scored, documented and saved in word format to facilitate the revision process.

\section{Data Extraction \& Data Storage}

The designed data extraction table is the easiest and comprehensive way to abstract the data from the included articles. The following criteria are the major categories for the extracted data: author/s and the article title, the study aim or purpose, the study design or literature type, CASP score, the type of professional context, and the type of knowledge. The Refwork articlearrangement software was used to store the retrieved data and this includes both the articles as well as the CASP tool. The stored data at this software is saved in PDF and word documents; the last format (word) was created to facilitate entering and documenting the changes during the review process. Furthermore, each CASP tool checklist includes the same Ref ID of the original article to maintain the reliability and accessibility of the articles.

\section{Data Analysis}

The initial advanced literature search with term wisdom, nursing, and nurses' retrieves 1257 articles. 157 studies based on the titles, and abstracts met the inclusion criteria. With attention to the full-text screening inclusion criteria, there were 16 articles fulfilled all the inclusion criteria of this review. Four articles were duplicated in a different database and two articles were missing. (Appendix Figure 2). The study findings demonstrate that, there are four major dimensions that include the concept of wisdom in nursing profession. These dimensions are:

a) Moral and ethical aspects $(n=2)$,

b) Nursing managements and leadership ( $n=2)$,

c) Clinical nursing experiences $(\mathrm{n}=3)$ and

d) Nursing education $(n=3)$ (Appendix Figure 2).

In another hand, Carper's patterns of knowledge identified that only four out of 14 articles include all four patterns of knowledge.

\section{Results and Discussion}

\section{Philosophical Views of Wisdom}

Socrates's View: Socrates initiated the early thought of wisdom [31]. He considered all virtuousness as a form of wisdom [31,32]. He strongly emphasized that this kind of wisdom allows person to have moral and ethical strength only when the individuals has intelligent and reasonable thoughts [32]. Socrates also asserted that the quality and moral understanding are the most important attribute to learn, although it cannot be thought [33]. Socrates's famous expression affirms that as he says: "...the greatest good for a man [is] to discuss virtue [excellence] every day and those other things about which you hear me conversing and testing myself and others, for the unexamined life is not worth living for men..." (West, ND, 38a p. 19-20). This suggests that wisdom is the highest level of individual virtues that help to examine human life.

Furthermore, deep understanding of quality of life and moral actions can be considered as major attributes of wisdom. The development of these attributes occurs only in the existence of intelligent and reasonable thoughts [32]. Socrates is also challenged the absolute human knowing, which in his view is always limited and fallible [34]. This indicates that human wisdom always be a tentative and questioned [35]. In contrast, he valued the process of knowing 
because it provides deeper understanding and examination of uncertain life experiences [34,35]. Epistemologically, Socratic view of wisdom values the process of experiences because it provides wiser knowledge that help individuals to understand different meanings and ways for truth [36]. The error of human knowledge is acceptable in Socratic philosophy and it is an inquiry in his wisdom view [36]. This concludes that Socratic proposition overcomes the human wisdom fallibility because it is open-ended and can involve anyone; requires further investigation and proves for the wrong ideas or knowledge and helps to overcome the prejudice and lack of confidence [36].

Plato's View: According to Plato, wisdom is a meaning of human satisfactions, which is in his view, is the only way for the best human life and their lives [37]. He stated that "...Men of Athens, I am grateful, and I am your friend, .... Good Sir, you are an Athenian, ...; are you not ashamed of your eagerness to possess as much wealth, reputation, and honors as possible, while you do not care for nor give thought to wisdom or truth, or the best possible state of your soul?" [37]. Afresh, this indicates that wisdom is the highest level of understanding for seeking a truth. Based on Smillie (ND) [34] illustration, there are three Platonic images of wisdom that exemplifies the meaning of understanding. These three images are Leaving the Cave: Wisdom as Enlightenment; The examined life: wisdom as care for the soul; and Wisdom as not knowing [33]. The following articulation is based on Smillie's illustration, though it involves some modifications to explain and propose the indicators of nursing wisdom.

Leaving the 'Over Medicalized Cave': "Wisdom as Enlightenment". Nursing wisdom is shown as getting out of the 'over medicalized' cave and coming to see human health as they really are. Historically, nurses have been forefront of developing holistic and complementary integrative care [38]. The Nightingale's and the bio-pscyho-social-spritusl-cultural models allowed nurses to value the role of the interpersonal relationship in their healing process [39]. However, the over medicalized healthcare context leaned and waved the foundation of holistic care within nursing profession [38,39]. For instance, the nurse practitioner movement that developed in the late 1960s led the nurses to become more medicalized and specialized in their scope of practice and in their skills and thoughts as well [39].

It's important to note that the health concerns outside the 'over medicalized cave' is not a complete break with being in the cave [34]. Nurses know about the scientific background of diseases and their pathophysiology, its medical and nursing diagnosis, manifestations, and the required skills and interventions [38]. However, to apply nursing wisdom nurses are required to no longer look at the 'over medicalized' "shadows" and ignoring the holistic care $[34,39]$. Leaving the 'over medicalized cave' maintains the principle of Patient's centralization, which allows nurses to seek for the new truth $[38,39]$. Though, wise nurses need to consider "truer way" not by seeking the "prototypes" for the copies that exist in the cave $[33,37,38]$. "Enlightenment" is different from our previous life, but not unrelated to it. This image of wisdom stresses that part of being wise is having "true understanding" [34].

The Examined Life-'Nursing Critical Reflection': Wisdom as Care for the Soul. Near the end of Plato's Apology, he suggested a second image of wisdom: the examined life [34]. "This is how the philosopher cares for his/her soul [37]. Based on Plato's view, thinking without examining the inner thought and personal changes ignore our deepest human need [34]. This is compatible with the principle of nursing critical reflection. Reflection is a state of mind that involves ongoing constitute of practice [40]. Nursing critical reflection includes reflectivity and reflexivity as major components $[40,41]$. It is a type of self-integration of the daily nursing experiences, which allows nurses for true knowledge $[40,41]$. Such knowledge empowers them to challenge the over medicalized stereotyped assumptions, ideological illusions, rigid social constructions, and cultural biases $[40,41]$.

A life focused on the question of its greatest good is a life lived to its fullest- "an excellent or virtuous life" [33]. This image of wisdom stresses the practical part of being wise, being able to put your understanding into practice, to have it make a difference in your life and the lives of others [34]. This indicates that a practical wise nurse is the one who demonstrates all patterns of nursing knowledge, controls the internal and external emotions, critically manages and prevents the potential risks, and assertively addresses the moral conflicts [42,43]. Furthermore, an effective ethical decision-making is an action that reflexes the nursing wisdom [42,44]. However, such reflexive action requires nurses to have the ability to reflect on their personal values $[9,41]$.

The optimal levels of morality and ethical aspects are reached when the nurse's virtues reveal and reflect justice for the patients $[42,43]$. Consequently, personal values are essential for dealing with day-to-day ethical, management, and leadership issues [42,44]. These help wise nurses to address their professional goals, shape their attitudes and feelings, consider their interests, and strengthen their confidence, which are required to guide their thinking, actions and interactions with patients [42,44].

Wisdom as Not Knowing: Nurses as Outsider vs Insider. Plato suggested that not knowing sometime is a type of wisdom. In his Apology he replied to Socrates's expression which is "...when I do not know, neither do I think I know"; Plato responded that "so I am likely to be wiser than he to this small extent, that I do not think I know what I do not know...I am better off than he is, ....for he knows nothing, and thinks that he knows. I neither know nor think that I know... I seem to have slightly the advantage of him. [37]." There is no evidence about such view in nursing literature. However, such view may provide wiser nursing knowledge and reactions specifically when conducting a scientific research. For instance, in qualitative research there is a huge debate about researcher being 
outsider vs insider. One of the major questions that arose is, should qualitative researchers be members of the population they are studying or should they not?

Based on Plato's views of wisdom of unknowing, it is logical to assume that a wise nurse researcher should balance the internal, intra, and external emotions while they conduct qualitative research. Dweyer \& Buckel asserted that there are complexities inherent in occupying the space between being insider vs outsider [45]. Fay et al. noted that each requires the other as he indicated, "There is no self-understanding without other-understanding" [46]. Nursing wisdom in this case could be considered as equilibrium that balances the ways in which we are different (unknowing) from others and the ways in which we are similar (knowing) $[45,46]$. It maintains this foundation that allows nursing scholars to manage their membership role of being both insider and outsider.

Aristotle View: Aristotle describes human wisdom as "knowledge about certain causes and principles" [47]. His view constructs understanding as a fundamental principle in human wisdom (Gartner, 2013). The wise man, in his view, is the man who seeks for ongoing process of knowing [48]. He believes that wise men are capable of teaching because they can rationalize and justify the knowledge rather than those who only accumulate knowledge because of memories and sensations $[47,48]$. This indicates that understating knowledge is the accurate methods to know a truth [48]. He asserted that, choosing to know something for the sake of knowledge is the truest example of knowledge [47,48] (Gartner, 2013). Therefore, in nursing it is important to gain knowledge for the sake of knowledge instead of for the temporary result it produces to maintain competent nursing care (Rhodes, Morris, \& Lazenby, 2011). Indeed, it will sustain the social and professional nursing identity because it empowers the nursing knowledge [6]. This powerful knowledge fulfills in nursing profession, and is therefore something that should be pursued in and of itself.

Aristotle classified human wisdom into Phronesis and Sophia (Figure 2): Aristotle Wisdom Classification - [5,47]. Phronesis in Oxford Dictionary of Philosophy is a Geek word means "intelligence" or "prudence" [5]. Based on Aristotle, this kind of wisdom focuses on human actions and their consequences to realize the wisest decision for humane interaction $[9,47,49]$. This indicates that Phronesis wisdom fits with the interpretative paradigm. Therefore, the social aspects of nursing identity and holistic care can be achieved because this paradigm constructs the nursing knowledge from social model. On the other hand, Sophia is a form of wisdom that focuses on intuition and scientific approach for spiritual, holy or religious knowledge for the sake of the wisest truth $[9,49]$. There is no clear definition of term Sophia in Oxford Dictionary of Philosophy. Art historians believe that Sophia was born of Silence according to Gnostic creation myths [50]. She gave birth to both male and female who together created all the elements of our material world [50].
Sophia is the beginning, the source of wisdom, and keeper of the knowledge of all that is righteous and just and known as the Mother of Wisdom [50]. Other theory attributed that Sophia was symbolized by the Dove of Aphrodite, which later became the dove that represents the Holy Spirit [50]. Sophia is also known as the mother of Faith, Hope, and Charity. They are Sofia's gifts to overcome the despair, confusion, and suffering that frame human life [50]. Sophia, in the art historian view, provides clear vision and understanding line the path that leads to the discovery of the meaning of life [50]. However, some scientific scholars identify Sophia as a form of wisdom that focuses on intuition and scientific knowledge for the sake of the wisest truth $[9,49]$. Either in art or scientific views of the Sophia wisdom, both suggest that this kind of wisdom is computable with empiricist paradigm. The logical positivism lens of the empiricist paradigm involves an absolute true. Accordingly, the nursing knowledge in Sophia wisdom should be objective, standardized, and generalized. Therefore, it maintains the foundation of nursing professionalism and principle of nursing autonomy.

\section{Knowledge Attributes of Nursing Wisdom}

Attributes are characteristics that provide a description of the concept. In this concept analysis three key knowledge attributes of nursing wisdom have been identified. These are self-effacement knowledge, accuracy knowledge, and experiential Knowledge.

Self-Effacement Knowledge: The philosophical overview of wisdom provides important character for a wise nurse. A wise nurse is the one who been internally involved in an epistemic selfconfidence. Indeed, the most knowledgeable nurses who know about their skills and ability are having highest self-effacement. Though, they claim to know things far beyond the scope of their expertise. Furthermore, wise nurses tend to acknowledge their fallibility, been reflective, introspective, and tolerant of uncertainty. Any acceptable theory of wisdom ought to be compatible with such characters. However, those characters are not, in and of themselves, definitive of wisdom. It is important to recognize that believing on some degree of having wisdom is a way of making effective decisions in uncertain circumstance. Having the belief that one is wise does not, in itself, eliminate the possibility that the person is wise. Nor does it guarantee the vice of arrogance. Nurses should believe that a wise nurse would have a healthy dose of epistemic self-confidence, appreciate that she/he is wise, and share her/his understanding of reality with the rest of healthcare personnel who could benefit from her/his wisdom. Thus, the belief that one is not wise is not required for wisdom.

Accuracy knowledge: A wise nurses restrict their confidence to propositions for which they have knowledge or, at least, to propositions for which they have excellent justification. This indicates that a wise nurse has to have an accurate about what she/he knows and what she/he does not know. This technique is consistence with the idea that Socrates's error as a wisdom. Wise 
nurse can make mistakes about what they know. However, a wise nurse should justify and explain the process of knowledge to identify the mistakes. It is really important to realize that a good justification is based on accurate knowledge process. For instance, one might argue that through Socrates questioning, he reveals not that his opponents lack knowledge because their beliefs are false, but he demonstrates that his opponents are not justified in holding the views they profess to know.

Failure to justify the knowledge process strongly impacts in nursing care and mainly on a reflective decision-making. Proving and demonstrating to appropriate justification is a doubled arrows line that provide and deductive the accurate knowledge. However, some nursing scholars may argue that one could be justified in believing a proposition, but not realize that she/he is justified. If that is a possible situation for a wise nurse to be in, then she/he might be justified, but fail to believe she has knowledge. Therefore, a wise nurse would always recognize the epistemic value of what she/he believes.

Experiential Knowledge: Nursing wisdom is a personal intellectual ability and professional skills, which developed from a complex and uncertain nursing experiences. These experiences allow nurses to improve their wisdom skills by challenging everyday nursing practice. This indicates that nursing wisdom is a cultivated process of experiential knowledge, which can be transformed, integrated, and contextualized. This knowledge and skills is accurate because it is derived from both theory and practice. These are transformed into a coherent and patient specific understanding of a given clinical encounter and balances between the art and since in nursing.

\section{Antecedents of Nursing Wisdom}

Antecedents capture the characteristics that precede a concept. The antecedents of nursing wisdom are experience, reflection, and care.

Experience: Experience is central to the acquisition of nursing wisdom and incorporates the clinical environment and the nurse's own inner reality. This inner reality is multi-layered and encompasses know how, beliefs and values about practice, as well as professional and cultural identity.

Reflection: Reflection is an essential element in nursing wisdom as it facilitates the development of a deeper understanding of clinical practice and professional identity. Wise nurses have to develop her reflective and reflexive skills that enable them to perceive the patient and uncertain clinical events from multiple perspectives. Indeed, a wise nurse has to have the ability to examine her/his practice with high levels of self-awareness and insight.

Care: Care is one of the core value in nursing discipline, however, only a wise nurse can provide the optimal level of nursing care. Nursing wisdom requires nurses to provide care that based on bio-pscyho-social-spritual-cultural model. Therefore, a wise nurse to distinguish the importance of Medicalized intervention, though be away from the over Medicalized care. Accordingly, a wise nurse can provide a holistic care with compassion and empathy in order to the interpersonal interaction and maintain her/his social identity. Furthermore, it challenges the injustice power that is created from the over Medicalized intervention.

\section{Types of Clinical Wisdom in Healthcare Context}

Clinical Wisdom: Sometimes referred to as practical or professional wisdom, which is types of Phronesis wisdom. Evidence addresses that Phronesis wisdom is widely used in the healthcare contexts. Its interpretations and utilizations vary from profession to another and are based on each discipline's context. The following section provides further articulation of the clinical wisdom in the healthcare context.

Medical Clinical Wisdom: Some medical scholars integrate clinical wisdom mainly to elaborate the concept of moral or ethical pluralism in relation to professionalism in modern medicine [51,52]. Baum-Baicker et al. [53] examined the concept of clinical wisdom to identify the key ethical dimensions in relation to mental healthcare [53]. They conceptualized the concept of clinical wisdom as efficient skills to develop virtue-based medical ethics [53]. They illustrated three main features of clinical wisdom, which include balancing the personal-professional-patient interests, accepting the difference, and maintaining professional and therapeutic manners regarding others [53].

Others investigate the relationship between clinical wisdom and evidence-based medicine. Parker [54], asserted that there is a constitute relationship between clinical wisdom and clinical judgment. In his view, failure of acknowledging this relationship will create perpetuate medical paternalism, which delay the adoption of properly evidence-based practice [54]. Marcum [52] examined the relationship between clinical wisdom and the quality of care in modern medicine. He emphasized that wisdom guides and empower clinical practice in a professional manner [52]. The absence of clinical wisdom in medicine curricula creates major pedagogical challenges [52]. In his view, the virtues-synergistic relationship should be taught and practiced by medical students, residence, and clinicians to improve the quality of medical care [52].

Nursing Clinical Wisdom: As it is indicated earlier, clinical wisdom is widely used in health care context and in nursing discipline as well. There is no clear definition that clarifies the meaning of the clinical wisdom. However, the included literature exemplifies the scope of utilization and some characteristic of clinical wisdom. Some nursing scholars studied clinical wisdom to elaborate the concept of moralism in relation to professionalism [7,55]. For instance, Uhrenfeldt et al. [10] used clinical wisdom to describe how proficient nurses' experiencing their practice. Their study composes the clinical wisdom based on responsibility, thinking and ethical discernment, and a drive for action [10]. They claim that the proficient or wise nurses are those who think critically, evaluate care policies, 
engage in professional relationships, respect dignity, understand silence, and create peering witness [10]. Furthermore, others claim that clinical wisdom is an essential element to identify the "good" nursing actions and skills [7]. Heggerty et al. [7] emphasize that the experience-based knowledge and individual moral commitment are the integral elements for the clinical wisdom. In their views, the wise nurses are those who make wise decisions that base on their "tacit knowledge [7]".

Indeed, they use the knowledge to balance the intrapersonal, interpersonal, and extra personal interests to achieve a "common good p. 236." [7]. Clinical wisdom exemplifies two clinical nursing habits, which are clinical grasp and clinical forethought [55]. Clinical grasp involves the ability to create a special knowledge to a specific group of patients, while the clinical forethought involves the ability to respond quickly and appropriately toward daily care events [55]. The authors consider that the clinically wise nurses have a wise clinical leadership and decision-making, which are essential in professionalism and perfectionism [55]. Clinical wisdom is also used as a pedgological framework in nursing education, mainly to illustrate the scope of practice and nursing skills, and to exemplify the concept of professionalism. Tarlie et al. [56] reported that a clinical wise nurse educator is the one who critically developed a clinically-based cases, enhances the student's anticipations, and providing strategies for clinical potential problems for students, simplifies the nursing and medical diagnoses, and manages lifesustaining physiological functions in a complex illness and unstable health situations [56].

There are different views about the characteristics of clinically wise nurse educator. Some scholars proposed that

a) Managing a learning-clinical crisis situation,

b) Providing learning-clinical comfort measures,

c) Being a role model and providing caring for patients families,

d) Preventing hazards in a technological environment,

e) Teach appropriate end-of-life care and decision making,

f) Having effective learning communication skills,

g) Enhancing the teamwork,

h) Maintain patient-student safety, and coaching and mentoring of others [57].

Crigger et al. [57] illustrate three major attributes for professionalism as a learning strategy by using clinical wisdom, which include the following:

a) Contextualizing the technical issues and social, cultural, and motional factors of a health problem;

b) Demonstrating self-capacities that involve accurate professional knowledge and moral characteristics; and c) Understanding the capacities of other by accepting personhood flexibility to perceived needs [57].

Haggerty et al. [7] develop a framework for clinical wisdom that has three dimensions in clinical and educational nursing, which are:

a) Balancing the good for another with the common good,

b) Recognizing the balance between affect and intellect, and

c) Acknowledging the role of tacit knowledge in wise clinical practice [7].

Other scholars added the spiritual care because is considerable uncertainty and misgiving by many nurses $[58,59]$. Clinical wisdom is a conceptualization of ongoing metaphors $[60,61]$. This indicates that a wise educator nurse is the one who involves tacit knowledge as a learning strategy rather than didactic teaching approaches $[62,63]$. Paton [62] distinguish three attributes of professional wisdom in nursing education, which are

a) The hegemony of structural design of the major nursing course;

b) The relationship between nursing theory and clinical practice; and

c) The learning atmosphere in both academic and clinical [62].

\section{Conclusion}

The concept of nursing wisdom is a new innovation in nursing discipline; however, the concept of Phornosis, sometimes referred as practical, clinical, or professional, wisdom has a huge debate in nursing literature. Wisdom in nursing is one of these concepts that empower professionalism and develops true nursing knowledge. These principles are essential to provide reflective judgments in a highly complex and uncertain situation in nursing discipline. Wisdom in general and nursing wisdom in specific is an important topic, though it is broad. Therefore, it is difficult to be defined and comprehend especially with the absence of clear definition and constitutes understating. Understanding what constitutes wisdom is essential to clarify nursing identity and the true meaning of professionalism. This paper provided deeper insight with different philosophical, and theoretical dimensions that concern nursing discipline and healthcare professions as well. It describes the different views, classifications, knowledge attributes and types of wisdom in nursing. A better understanding of nursing wisdom and its attributes are essential for learning how to understand the meaning of competent care which is essential to recognize nursing identity and the meaning of professionalism.

Rodgers' [26] evolutionary method is utilized to describe this abstracted concept, hoping for further scholarly contribution that may used to initiate nursing wisdom theory. The goal of using the evolutionary concept analysis is to 'clarify and develop' concepts rather than describe their essence [26]. The method 
of evolutionary concept analysis is an ideal model that suits the goals of the proposed concept. An integrative review outlines a number of complex and challenging features about integration wisdom in nursing profession. The notions of 'true understanding' and 'reflective and reflexive judgment' are the main aspcts of nursing wisdom. Based on the presented philosophical overview, the dynamic of understanding, seeking for knowing, and justified reflections expand the nursing knowledge to achieve holistic care in contingent and unique context. These notions of reflection and reflexive balance between knowing, doing, and seeking to understand the use of nursing skills in contexts characterized by complexity and uncertainty. Considering nursing wisdom as a conceptual framework, expands nursing thinking to articulate and develop strategies that overcome 'over Medicalized cave', indeed it optimizes the holistic nursing care to the highest.

Furthermore, nursing wisdom is on-going process that requires personal virtues, intellectual abilities, and reasonable thoughts. Accordingly, a wise nurse could easily maintain her/ his social identity by considering the interpersonal relationships, which enhances the effective social integration. It also improves the professional identity and autonomy by empowering accurate nursing knowledge and epistemic knowing process. These two advantages of nursing wisdom will achieve by three key knowledge attributes of nursing, which are self-effacement knowledge, accuracy knowledge, and experiential Knowledge. Experience, reflection, and care are the major antecedents of nursing wisdom. Clinical nursing wisdom has an overlapped types and characteristics in a various nursing profession. The study findings demonstrate that, there are four major dimensions that include the concept of wisdom in nursing profession. These dimensions are moral and ethical aspects, nursing managements and leadership, clinical nursing experiences and nursing education.

\section{Ethics approval and consent to participate}

Not applicable.

\section{List of abbreviations}

None.

\section{Data Availability}

Not applicable.

\section{Conflicts of Interest}

The author declares that there is no conflict of interest regarding the publication of this paper.

\section{Funding Statement}

Not applicable.

\section{Authors' contributions}

NB prepared, organized, conceptualized and interpreted the data of this manuscript.

\section{Acknowledgment}

The author acknowledge the effort of Dr. Carolyn Pierce who was an assistant professor in Decker School of Nursing at Binghamton University for her effort support and sharing her opinions during the preparation of the manuscript.

\section{Supplementary Materials}

Not applicable.

\section{References}

1. Feldenkrais M, Beringer E (2010) Embodied Wisdom: the collected papers of Moshe Feldenkrais. North Atlantic Books, U.S. ISBN 10:1556439067.

2. Fulcher L (2001) Cultural Safety: Lessons from Maori Wisdom. Reclaiming children and youth, Justice \& Reconciliation 10(3): 153-157.

3. Purushothaman (2014) Words of Wisdom: 1001 Quotes \& Quotations. Center for Human Perfection. India (Volume 70).

4. Hoeckner B (2013) Can our body be wise? Center of practical wisdom. Retrieved from: https://wisdomcenter.uchicago.edu/news/discussions/can-our-bodies-be-wise.

5. Blackman L (2008) The body: the key concepts. Berg. U.S.A ISBN 13:9781-84520-589-8.

6. Yazdannik A, Yekta ZP, Soltani A (2012) Nursing professional identity: an infant or one with Alzheimer, Iranian Journal of Nursing and Midwifery Research 17(2 Suppl1): S178-S186.

7. L Haggertly, P Grace (2008) Clinical wisdom: the essential foundation of " good" nursing care. Journal of Professional Nurses 24(4): 235-240.

8. Topaz (2013) Invited editorial: the hitchhiker's guide to nursing informatics theory: using the data-knowledge-information-wisdom framework to guide informatics research. Online Journal of Nursing Informatics (OJNI) 17(3).

9. Mc Kie A, Baguley F, Guthrie C, Jackson C, Kirkpatrick P, et al. (2012) Exploring clinical wisdom in nursing education. Nursing Ethics 19(2): 252-267.

10. Unhrebfeldt L, Hall E (2007) Clinical wisdom among proficient Nurses. Nursing Ethics 14(2): 387-398.

11. WR Cowling M, Shuttel M, Todd (2006) Hall's essay on an authentic meaning of medicalization: An extended discourse. Advances in Nursing Science 29(4): 291-304.

12. Silva K, Sena R (2013) Health promotion: Criticism of every-days life medicalization practice. Journal of Nursing Education and Practice 3(9).

13. M Denny (1999) This is who I am, don't let them move me, Autonomy in nursing homes, Quinnipiac Health Law 2(2): 203-225.

14. (2008) American Nurses Association [ANA], Nursing informatics: Scope and standards of practice. nursesbooks.org, Silver Spring, MD, USA.

15. J Fawcett, S De Santo Madeya (2013) Contemporary nursing knowledge: Analysis and evaluation of nursing models and theories. ( ${ }^{\text {rd }}$ Edn.). F.A Davis, Philadelphia, USA.

16. N Klebanoff, D Hess (2013) Holistic nursing: Focusing on the whole person. American Nurse Today, 8(10), retrieved from http://www.americannursetoday.com/holistic-nursing-focusing-on-the-whole-person/.

17. Monti EJ, Tingen MS (1999) Multiple paradigms of nursing science. Advanced Nursing Science 21(4): 64-80.

18. Risjord M (2011) Nursing knowledge: Science, practice, and philosophy. Feminist Appropriation of Standpoint Epistemology. Blackwell Publishing, Oxford, UK.

19. Wall M, Carraro T (2009) Kuhn's revolutionary theory and its influence on the construction of nursing knowledge. Maio-junho 17(3): 417-422. 
20. Rodgers B (2005) Developing nursing knowledge: Philosophical traditional and influences. Lippincott Williams \& Wilkins, Philadelphia, USA, ISBN 0-7817-4708-2.

21. J Jackson (2015) Nursing paradigms and theories: A primer. Athabasca University, Canada.

22. N Mackenzie, S Knip (2006) Research dilemma: Paradigms methods and methodologies. Issues in Educational Research 16 Retrieved from http://www.iier.org.au/iier16/mackenzie.html.

23. Racher F, Robinson S (2002) Are Phenomenology and Postpostivism Strange Bedfellow? Western Journal of Nursing Research 25(5): 464 581.

24. Villiers MR (2005) Three approaches as pillars for interpretive information systems research: Development research, action research, and grounded theory. Proceedings of Saicist 111-120.

25. Schwandt T (1994) Constructivist, interpretivist approaches to human inquiry. Denzin, Norman K, Lincoln, Yvonna S (Eds.)., Handbook of Qualitative Research,Thousand Oaks, CA, pp,118-137.

26. Rodgers ST (2000) The role of nursing theory in standards of practice: a Canadian perspective. Nursing Science Quarterly 13: 360-262.

27. Tofthagen R, Fegerstrom LM (2010) Rodger's evolutionary concept analysis-a valid method for developing knowledge in nursing science. Scandinavian Journal of Care Sciences 24(1): 21-31.

28. Rodgers B, Knafl K (2000) Concept development in nursing: Foundation, techniques, and applications. Elsevier. Philadelphia, PA, USA.

29. (2009) Center for Review \& Dissemination. CRD's guidance for undertaking reviews in healthcare. Systematic reviews, York University, UK.

30. Oxman AD, Cook DJ, Guyatt GH (1994) Users' guides to the medical litarture. VI. How to use an overview. Evidence-Medicine working group. The Journal of the American Medical Association 272(17): 1367-1371.

31. WC Guthrie (1990) A history of Greek philosophy: Volum 6, Aristotles: An encounter. Cambridge University Press.

32. CP Long (2012) The ethics of ontology: A structural critique of the Carter and Reagan years. SUNY Press.

33. S Gallagher (1992) Hermeneutics and education (self-understanding and phronosis). SUNY Press.

34. Smillie WM, Three Platonic images of wisdom. Carroll.edu. (ND).

35. L Marinoff (2012) Plato not Prozac! Applying central wisdom to everyday problems. Harper Collins Publisher. NY USA.

36. Roochink D (2007) Of art and wisdom: Plato's understanding of tachne The Pennsylvania State University Press, PA, USA.

37. Plato (1978) The Apology, in The Collected Dialogues of Plato, Edith Hamilton and Huntington Cairns (Eds.), Princeton, Princeton University Press, New Jersey, United States.

38. Sparber A (2001) State boards of nursing and scope of practice of registered nurses performing complementary therapies. Online Journal of Issues in Nursing 6(3).

39. Zahourek R (2013) The advanced practice nurse and complementary therapies. In Joel, Lucille (Eds.) Advanced Practice Nursing; Essentials of Role Development, (3 ${ }^{\text {rd }}$ Edn.)., FA Davis, Philadelphia, USA

40. C Bulman, S Schutz (2013) Reflective practice in nursing. Wiley Blackwell, UK. ISBN: 978-0-470-65810-9.

41. Woods M, Murfet G (2015) Australian nurse practitioner practice: Value adding through clinical reflexivity, Nursing Research and Practice 1-14.
42. Cathcart EB, Greenspan M (2013) The role of practical wisdom in nurse manager practice: Why experience matters. Journal of Nursing Management 21(7): 964-970.

43. MJ Cook, HI Leathard (2004) Learning for clinical leadership. Journal of Nursing Management 12(6): 436-444.

44. Weaver K, Morse J, Mitcham C (2008) Ethical sensitivity in professional practice: Concept analysis. Journal of Advanced Nursing 62 (5): 607-618.

45. S Dweyer, J Bukcle (2009) The space between: On being an insider-outsider in qualitative research. International Journal of Qualitative Methods 8(1): 54-63.

46. B Fay (1996) Contemporary Philosophical of Social Science. Blackwell, Oxford, UK, pp. 278.

47. R Mc Keon (1941) The Basic Work of Aristotle. Random House, USA.

48. Ryan S (2014) “Wisdom", The Stanford Encyclopedia of Philosophy (Winter 2014 Edn), Edward N. Zalta (Eds.).

49. Wredenbach E (1970) Nurse's Wisdom in Nursing Theory. American Journal of Nursing 70(5): 1057-1062.

50. C Matthewes (2001) Sophia: Goddess of Wisdom, Bride of God. Quest Books, India.

51. L Kaldjian (2010) Teaching practical wisdom in Medicine through clinical judgment, goals of care, and ethical reasoning. Journal of Medical Ethics 36(9): 558-562.

52. J Marcum (2013) The role of empathy and wisdom in medical practice and pedagogy: confronting the hidden curriculum. Journal of Biomedical Education 1-8.

53. C Baum Baicker, D Stisti (2012) Clinical wisdom in psychoanalysis and psychodynamic psychotherapy: a philosophical and qualitative analysis. Journal of Clinical Ethics 23(1): 13-27.

54. Parker M (2002) Whither our art? Clinical wisdom and evidence-based medicine. Medicine, healthcare and philosophy 5(3): 273-280.

55. P Benner, P Hooper Kyriakrdis, D Stannard (2011) Clinical wisdom and intervention in acute and critical care: A thinking-in-action approach, ( $2^{\text {nd }}$ Edn.). Spring Publishing Company, New York, USA.

56. Tariler DS, Johson JL, Whyte NB (2003) Voices from the wilderness: an interpretive study describing the role and practice of outpost nurses. Canadian Journal of Public Health 94(3): 180-184.

57. N Crigger, N Godfrey (2011) The Making of Nurse Professionals: A Transformational, Ethical Approach. Jones \& Bartlett. Sudbury, MA, CA.

58. Swinton J (2001) Spirituality and Mental Health Care: Rediscovering a "forgetting" Dimension. Jessica Kningsley Publisher. London \& Philadelphia, USA.

59. Silva K, Sena R (2013) Health promotion: Criticism of every-days life medicalization practice. Journal of Nursing Education and Practice 3(9).

60. R Edmondson, J Pearce (2007) The practice of healthcare: Wisdom as a model. Medicine. Health Care and Philosophy 10(3): 233-244.

61. Myrick F, Yonge 0, Billay D (2010) Perceptorship and practical wisdom: A process of engaging in authentic nursing practice. Nurse Education in Practice 10(2): 82-87.

62. Paton BI (2007) Knowing within: practice wisdom of clinical nurse educators. The Journal of Nursing Education 46(11): 488-495

63. West T, Plato's apology of Socrates: An inter perception, with a new translation. Cornell University Press, ND. 
ISSN: 2574-1241

DOI: 10.26717/BJSTR.2019.23.003859

Najla A Barnawi. Biomed J Sci \& Tech Res

(C) This work is licensed under Creative

Submission Link: https://biomedres.us/submit-manuscript.php

$\begin{array}{ll}\text { BIOMEDICAL } & \text { Assets of Publishing with us } \\ \text { RESEARCHES } & \text { - Global archiving of articles } \\ \text { - Immediate, unrestricted online access } \\ \text { - Rigorous Peer Review Process }\end{array}$

